\title{
Gestão Ambiental na Educação Básica: A realidade de escolas da rede estadual de ensino em Iguatu, Ceará, Brasil
}

Environmental management in basic education: the reality of schools in the State schools in Iguatu, Ceará, Brazil

\author{
Alzeir Machado Rodrigues ${ }^{1}$, Maria Virlene de Araujo Rodrigues ${ }^{2}$ e Môngolla Keyla \\ Freitas de $\mathrm{Abreu}^{3}$, Jones Baroni Ferreira de Menezes ${ }^{4}$ \\ ${ }^{1}$ Mestrando, Mestrado Acadêmico em Sociobiodiversidade e Tecnologias Sustentáveis, Universidade da \\ Integração Internacional da Lusofonia Afro-Brasileira, Redenção, CE, Brasil \\ ${ }^{2}$ Graduanda, Curso de Ciências Biológicas, Universidade Estadual do Ceará, Iguatu, CE, Brasil \\ ${ }^{3}$ Mestranda, Mestrado em Desenvolvimento Regional Sustentável, Universidade Federal do Cariri, Juazeiro \\ do Norte, CE, Brasil \\ ${ }^{4}$ Mestre, Mestrado em Ciências Fisiológicas, Universidade Estadual do Ceará, Fortaleza, CE, Brasil
}

\begin{abstract}
Resumo
A gestão ambiental vem sendo uma temática bastante discutida no mundo, frente às ações antrópicas, consistindo numa forma de administração que busca minimizar os efeitos causados ao meio ambiente. Diante disso, observa-se a necessidade de desenvolvimento de uma gestão ambiental no espaço escolar, o que torna-se necessário uma investigação para esclarecer a realização de tal prática. Esse estudo trata de uma pesquisa descritiva, de abordagem quantitativa e qualitativa. A população e amostra escolhidas foram os professores, coordenadores e gestores de duas escolas de Ensino Médio do município de Iguatu-Ceará, perfazendo um total de 45 participantes. A coleta de dados foi realizada a partir da aplicação de um questionário contendo 15 questões objetivas e subjetivas, aplicado durante o mês de maio 2015. Os dados foram analisados descritivamente. Diante do observado, os professores conhecem o termo gestão ambiental (62\%), sendo capazes de levantar aspectos relevantes sobre preservação dos recursos naturais. No desenvolvimento das temáticas ambientais, os alunos participam de projetos ligados ao tema (84\%) e as escolas quase sempre (58\%) promovem eventos sobre o desenvolvimento sustentável e questões pertinentes. Em meio aos resultados obtidos, observa-se que os professores apresentam uma concepção preliminar sobre a gestão ambiental, embora alguns desconheçam este conceito, e que as escolas promovem, mesmo que parcialmente, atividades que são promotoras do desenvolvimento sustentável.
\end{abstract}

Palavras-chave: Sustentabilidade. Meio ambiente. Educação.

\begin{abstract}
Environmental management has been a much discussed topic in the world, in the face of human actions, consisting of a form of administration that seeks to minimize the effects to the environment. Therefore, the need to develop an environmental management in the school environment is observed, which an investigation it is necessary to clarify the achievement of such a practice. This study is a descriptive research, quantitative and qualitative approach. The population sample was chosen and teachers, engineers and managers from two high schools in the city of Iguatu, Ceará, totaling 45 participants. Data collection was performed from the application of a questionnaire containing 15 objective and subjective questions, applied during the month of May 2015. The data were analyzed descriptively. Before observed, teachers know the term environmental management (62\%), being able to raise relevant issues on preservation of natural resources. The development of environmental issues, students participate in projects related to the theme (84\%) and schools almost always (58\%) promote events on sustainable development and relevant issues. Among the results, it is observed that teachers have a preliminary design on environmental management, although some unfamiliar with this concept, and that schools promote, even partially, activities which promote sustainable development.
\end{abstract}

Keywords: Sustainability. Environmental. Education. 


\section{Introdução}

A gestão ambiental consiste numa forma de administração que busca minimizar os efeitos que uma dada instituição pode causar ao meio ambiente, como por exemplo: a poluição em suas diversas formas, o extrativismo e as interferências junto à comunidade biótica. Além disso, torna-se possível a identificação das possíveis causas, e, logo em seguida, formas cabíveis de corrigir os danos causados à natureza.

A sustentabilidade ambiental vem sendo foco de diversas discussões em todo o mundo e as políticas de gestão ambiental buscam enfatizar, em sua forma de gerência, hábitos que possam ser desenvolvidos nos mais amplos espaços, promovendo um desenvolvimento sustentável, e em consequência, a qualidade de vida das gerações atuais sem prejudicar as futuras, garantindo recursos naturais e demais fatores que promovem a vida para as próximas gerações.

Segundo Fernandes (2010) o capitalismo vem sendo difundido na sociedade a nível mundial, e, atualmente, tem-se uma realidade na qual os rendimentos financeiros permeiam acima de qualquer outro valor. Entretanto, o maior agravamento é para o meio ambiente, visto que através dos avanços nos meios tecnológicos e industriais o extrativismo encontra-se cada vez mais acentuado no mundo.

A gestão ambiental, portanto, surge como uma perspectiva de solução, tanto nas instituições públicas como nas privadas, de reduzir os impactos ao meio ambiente e promover uma gerência voltada para as questões pertinentes ao desenvolvimento sustentável (KRAEMER, 2004).

Sendo a escola um espaço de formação humana onde são desenvolvidas as habilidades necessárias para o convívio social e a inserção de pessoas qualificadas no mercado de trabalho, é de extrema necessidade que nele seja disponibilizado o desenvolvimento de uma gestão educacional voltada para as questões ambientais, assim como instigar que os seus integrantes busquem formas de minimizar as agressões ocasionadas ao meio ambiente. Para Gouvêa (2006) a educação ambiental deve estar intimamente ligada aos conteúdos trabalhados em sala de aula, de modo a promover, durante o processo ensino-aprendizagem, uma sensibilização para questões associadas à preservação ambiental.

Em meio ao exposto anteriormente, surgem indagações de como as escolas trabalham a gestão ambiental em seu espaço de formação social, e alguns pontos tornam-se necessários de esclarecimentos: será que as escolas realmente promovem uma gestão ambiental de forma eficaz para a assimilação dos alunos sobre as questões pertinentes à preservação do meio ambiente?

Diante da necessidade de desenvolvimento de uma gestão ambiental no espaço escolar, e tendo em vista que nem sempre as escolas preocupam-se com as questões associadas à preservação dos recursos naturais, torna-se necessária uma investigação para esclarecer algumas dúvidas associadas a esta questão.

\section{Metodologia}

Este estudo trata-se de uma investigação do tipo descritiva, com uma abordagem do tipo quantitativa e qualitativa. A pesquisa descritiva "visa a descrever as características de determinada população ou fenômeno ou o estabelecimento de relações entre variáveis" (PRODANOV; DEFREITAS, 2013).

A abordagem quantitativa é empregada em diversos tipos de pesquisa, dentre elas as descritivas, em especial ao buscar estabelecer relação causa-efeito e em alguns casos pela facilidade de descrever a complexidade de certas hipóteses ou problemas, fazendo uma análise das variáveis envolvidas, de modo a compreender e classificar processos sociais complexos, onde normalmente usa-se de recursos ou métodos estatísticos para expor resultados encontrados no estudo. Já a pesquisa qualitativa não requer o uso de ferramentas estatísticas e o ambiente será a fonte direta para se realizar os 
procedimentos de coleta de dados, sendo o pesquisador um elemento crucial no processo de pesquisa. Esta pesquisa é significativamente descritiva e os pesquisadores costumam analisar os dados pelo método indutivo. Nesse tipo de pesquisa o pesquisador manterá um contato direto com o objeto do estudo em questão, necessitando de forma intensiva de um contato com o campo de estudo (PRODANOV; DE-FREITAS, 2013).

A escolha pela abordagem quanti-qualitativa, nesta proposta de investigação, deve-se à natureza de seu objeto de estudo e aos objetivos que se pretende alcançar. Nesse sentido, concorda-se com Matos e Vieira (2002) quando apontam a necessidade de sintonia entre as pesquisas quantitativas e qualitativas, estabelecendo entre essas duas vertentes uma relação de complementariedade, de modo que os números apresentam valores, emoções e precisam ser traduzidos em contextos diversos. As autoras ainda discutem sobre as possibilidades de estudo com relação aos significados dos dados estatísticos da pesquisa.

Os sujeitos dessa pesquisa foram os professores, coordenadores e diretores de duas escolas públicas (A e B) da cidade de Iguatu-CE. A Escola A possui 12 professores de sala de aula e 3 gestores. Para a seleção da amostra da pesquisa utilizaremos um nível de confiança de $90 \%$ e erro amostral de $10 \%$, sendo entrevistados 13 integrantes dessa população em estudo. Já na escola B tem-se 57 professores e 2 gestores, utilizaremos, portanto, os mesmos parâmetros da amostra anterior, 32 entrevistados, selecionados aleatoriamente. Todos os envolvidos assinaram os termos de consentimento livre e esclarecido, dando consentimento da participação da pesquisa, bem como a confidencialidade e anonimicidade.

Nessa fase da pesquisa, logo após a coleta dos dados, o pesquisador detinha, condições suficientes para realizar a descrição dos dados e, em seguida, fazer a interpretação daqueles já tabulados que foram organizados em uma etapa antecedente. A análise foi feita de modo a atender aos objetivos expostos no início da pesquisa, usando-se da comparação e do confronto dos dados e provas para a confirmação ou a rejeição das possíveis hipóteses do estudo (PRODANOV; DE-FREITAS, 2013).

\section{Resultados e Discussão}

O presente estudo foi realizado com 45 professores da educação básica da cidade de Iguatu, que atuam nas escolas EEEP Lucas Emmanuel Lima Pinheiro e LICEU de Iguatu - Dr. José Gondim, sendo 20 do sexo feminino e 25 do sexo masculino.

Os interlocutores desta pesquisa foram identificados com os seguintes cognomes: professor P1; P2; P3; P4; P5 P6; P7; P8; P9; P10; P11; P12; P13; P14; P15; P16; P17; P18; P19; P20; P21; P22; P23; P24; P25; P26; P27; (P28); (P29); (P30); P31; P32; P33; P34; P35; P36; P37; P38; P39; P40; P41; P42; P43; P44; $\mathrm{P} 45$.

Em relação ao grau de formação dos indivíduos, observou-se que a maioria (51\%) possui pósgraduação em nível de especialização, e que apenas $2 \%$ dos professores, atuantes nas referidas escolas, não possuem ainda o nível superior concluído (GRÁFICO 01).

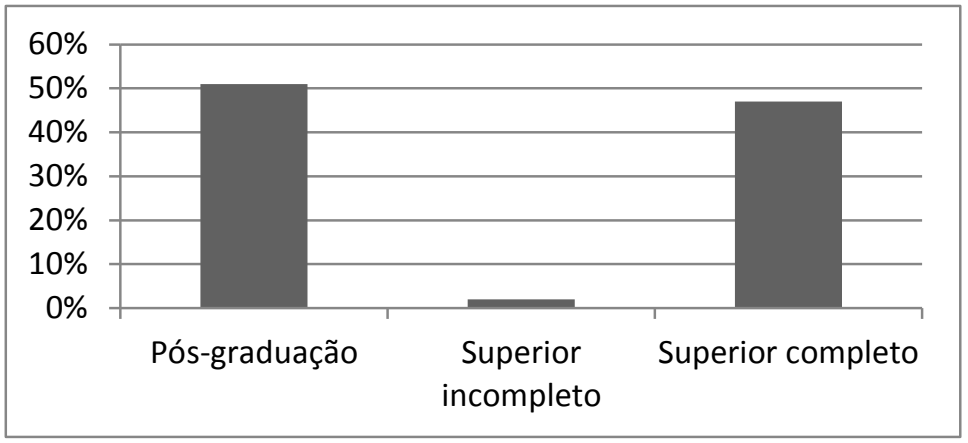

Gráfico 01 - Nível de escolaridade dos participantes da pesquisa

Fonte: Elaborado pelos autores. 
Os professores que colaboraram para o referente estudo atuam no ensino das disciplinas de Língua Portuguesa, Língua Inglesa, Língua Espanhola, Educação Física, Informática, Artes, Formação para a Cidadania, História, Geografia, Sociologia, Filosofia, Biologia, Física, Química e Matemática, e na coordenação pedagógica e direção escolar.

\subsection{Conceitos em Gestão Ambiental}

Sobre os conceitos associados à gestão ambiental, o primeiro a ser indagado foi o que o entrevistado entende por meio ambiente. Diante desse questionamento, P26, professor de História, definiu meio ambiente da seguinte forma "É o conjunto de seres animados e inanimados que, de forma organizada, executam atividades interdependentes necessárias à continuação da vida."

Tal responda pode é corroborada por Brasil (1981), quando, no art. 3ํㅡ, I, da Lei nº 6.938/81 que trata sobre a Política Nacional do Meio Ambiente, define gestão ambiental como sendo "o conjunto de condições, leis, influências e interações de ordem física, química e biológica, que permite, abriga e rege a vida em todas as suas formas".

Sobre a definição do termo meio ambiente existem diversas discussões sobre a sua redundância, visto que as duas palavras significam a mesma coisa, e frente a essa realidade não seria necessário a utilização dos dois termos (FREITAS, 2001). Porém, na visão de alguns estudiosos esta terminologia tem como premissa dar uma maior ênfase às problemáticas encontradas na relação homem e natureza.

Diante das respostas obtidas pelos entrevistados, algumas foram bastante diretas, como as dos participantes P6, P22, P23, P27, P28, P29, P31, P40 e P41, que definiram meio ambiente simplesmente como sendo "o espaço que nós vivemos". Rodrigues (2012) fala sobre as crenças ecocêntricas e antropocêntricas, onde na primeira o homem se sente parte do meio e isso implica uma maior preocupação frente às questões que envolvem a preservação do meio ambiente. Já a crença antropocêntrica vê o homem como sendo o centro do universo, e este não se insere dentro do conceito de meio ambiente. Diante desta análise antropológica, consegue-se perceber que até mesmo nas definições mais diretas e superficiais o homem se insere como sendo parte do meio, e desta forma pode-se considerar que ele assume uma maior preocupação com as questões ambientais.

A preocupação, em aspectos de gestão ambiental, que o homem começa a demonstrar frente aos aspectos econômicos, políticos e sociais, vem sendo percebida de forma significante desde o início da década de 1970, onde as ciências da gestão, em sua ampla área de atuação, estão incorporando as questões relativas à preocupação que é crucial para o desenvolvimento dos diversos níveis sociais e administrativos (CUPERSCHMID, 2015).

Questionou-se também sobre uma temática de bastante repercussão nas campanhas de preservação do meio ambiente, a reciclagem. Neste parâmetro, observa-se que os principais termos recorrentes nas respostas estão ligados a reaproveitar, reutilizar, converter e transformar, pontos focais das transformações dos resíduos sólidos, conforme descrito a seguir nas concepções que os professores têm sobre o termo.

\begin{tabular}{|l|l|}
\hline Participantes & \multicolumn{1}{|c|}{ Concepção de reciclagem } \\
\hline P1 & $\begin{array}{l}\text { "Reaproveitar o máximo possível daquilo que usamos e comemos para ser } \\
\text { reutilizado novamente". }\end{array}$ \\
\hline P5 & "Processo de conversão de materiais." \\
\hline P10 & "Transformar um produto, que já foi utilizado e descartado, em um novo". \\
\hline P15 & $\begin{array}{l}\text { "É o processo que usa transformar materiais usados em novos produtos, com o } \\
\text { objetivo de ser reutilizado". }\end{array}$ \\
\hline
\end{tabular}

Quadro 01 - Concepção de reciclagem pelos professores.

Fonte: Elaborado pelos autores.

De acordo com Brasil (2010), a reciclagem é o processo de transformação dos resíduos sólidos que envolve a alteração de suas propriedades físicas, físico-químicas ou biológicas, com vistas à 
transformação em insumos ou novos produtos, observadas as condições e os padrões estabelecidos pelos órgãos competentes. Esses resíduos podem ser provenientes de residências, fábricas, lojas e escritórios, por exemplo (RODRIGUES, 1997). Portanto, o termo reciclagem engloba uma série de novos conceitos que são utilizados na sua definição, pois envolve diversos aspectos que podem agir a depender do tipo de resíduo que está sendo utilizado no processo.

Dentre as definições expostas pelos entrevistados, a que melhor corrobora com os autores supracitados é a de P8 quando define que:

\footnotetext{
“Reciclagem é o processo que visa transformar materiais usados em novos produtos com vista a sua reutilização. É através desse processo que os materiais que seriam destinados ao lixo permanente podem ser reaproveitados. É um termo que tem sido cada vez mais utilizado como alerta para a importância da preservação dos recursos naturais e do meio ambiente".
}

Em relação à definição do termo gestão ambiental, um percentual considerável de educadores (38\%) desconhecem este conceito, além disso, dentre os que afirmaram conhecer (62\%), alguns não conseguiram definí-lo (GRÁFICO 02). Entre as definições feitas pelos entrevistados, a maioria conceituou apenas como a preservação do meio ambiente, porém P8 e P9 trouxeram uma definição mais complexa do termo, sendo a de P8 retratada a seguir: "É um sistema de administração voltado para as empresas visando a sustentabilidade. E objetivando desenvolver práticas e métodos administrativos que possam reduzir ao máximo o impacto ambiental das atividades econômicas nos recursos da natureza".

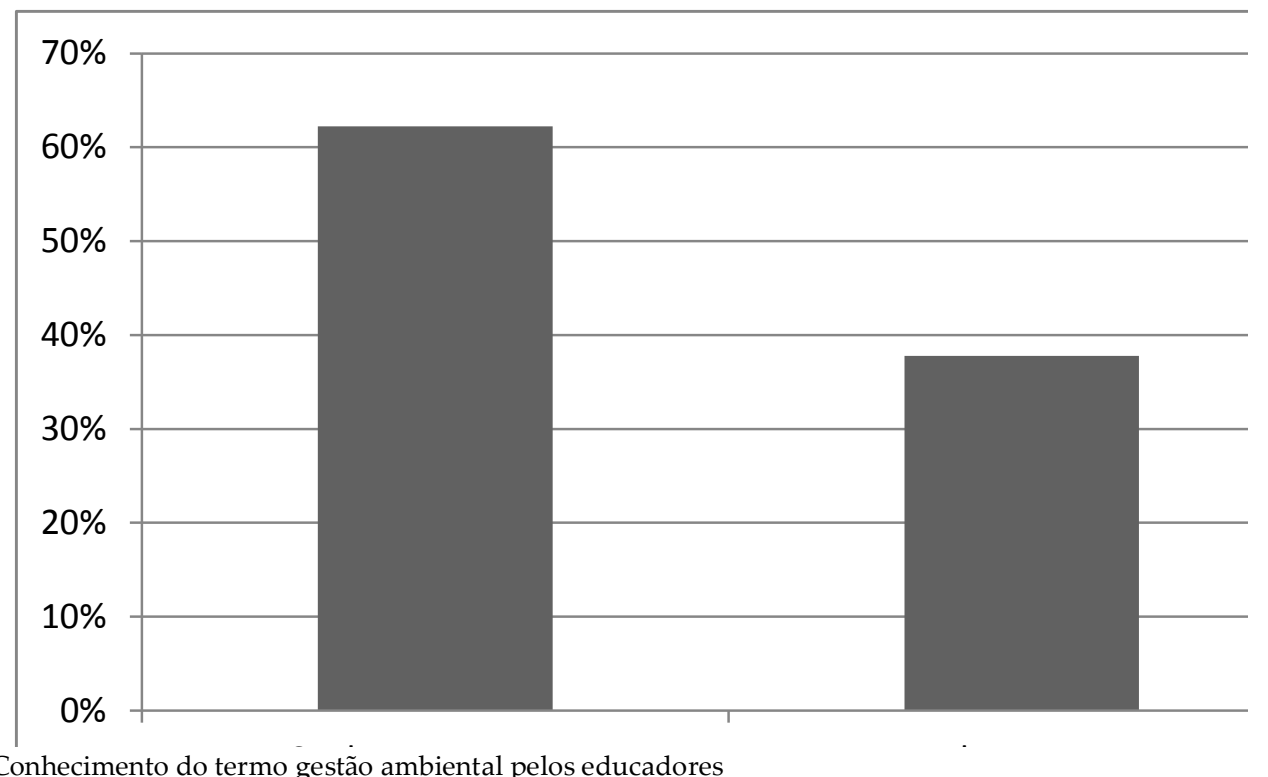

Gráfico 02 - Conhecimento do termo gestão ambiental pelos educadores Fonte: Elaborado pelos autores.

O conceito retratado por P8 nos remete ao afirmado por Couto (2009) onde a gestão ambiental é um conjunto de ações que englobam políticas públicas, o setor produtivo e o social de uma forma genérica, onde são desenvolvidas atividades que estimulem o uso racional e sustentável dos recursos naturais, ligando, portanto, aspectos da conservação e do desenvolvimento em todos os níveis.

Os aspectos que são apontados na Quadro 02 se referem aos posicionamentos de alguns dos entrevistados. Deste modo, é perceptível a concepção de P5 sobre a função que a escola tem na formação de cidadãos conscientes de sua função social, e do contexto que o relaciona com a preservação da natureza. Menezes e Rodrigues (2015) corroboram com a ideia do papel que a escola tem na formação social dos estudantes, frente às questões ambientais, motivando-os ao desenvolvimento de atitudes sustentáveis que possibilitem um melhor aproveitamento dos recursos naturais. 


\begin{tabular}{|c|c|}
\hline Participantes & Aspectos relevantes \\
\hline P5 & $\begin{array}{l}\text { "A Escola é um espaço de formação, os professores são peças } \\
\text { fundamentais no processo de sensibilização dos problemas sociais, pois } \\
\text { se busca desenvolver nos educandos atitudes de conservação e respeito a } \\
\text { natureza". }\end{array}$ \\
\hline P10 & $\begin{array}{l}\text { "Educação e reeducação da comunidade chamando atenção para os } \\
\text { problemas ambientais e para as melhores formas de contorná-los". }\end{array}$ \\
\hline P15 & $\begin{array}{l}\text { "A coleta seletiva que acontece na escola e a conscientização junto aos } \\
\text { alunos sobre o lixo". }\end{array}$ \\
\hline P20 & "A coleta seletiva que é realizada na escola". \\
\hline P25 & $\begin{array}{l}\text { "A diminuição de poluentes como descartáveis e produtos não } \\
\text { biodegradáveis". }\end{array}$ \\
\hline P30 & "Recomendar o uso adequado dos recursos naturais". \\
\hline P35 & "O plantio de mudas, recolhimento de garrafas pet". \\
\hline $\mathrm{P} 40$ & $\begin{array}{l}\text { "Estresse - Uma boa jardinagem diminui o estresse. A arborização } \\
\text { diminui a sensação de calor e desconforto". }\end{array}$ \\
\hline P45 & "Reaproveitar e reutilizar". \\
\hline
\end{tabular}

Os entrevistados P5, P15, P20, P25, P30, P35, P40 e P45 trazem exemplos relacionados com a realidade das escolas nas quais trabalham, onde são desenvolvidas ações que viabilizam a sustentabilidade, e, desta forma, promovem a gestão ambiental dentro da escola. Alcócer et. al. (2015) também retrata as questões de desenvolvimento de práticas pedagógicas voltadas para o estímulo ao uso consciente dos recursos naturais, e as práticas englobadas nas tecnologias sustentáveis que são exploradas nas escolas públicas estaduais. Deste modo, observa-se neste trabalho, que algumas técnicas são pouco difundidas em sala de aula.

\subsection{Gestão Ambiental na Prática: o dia-a-dia na escola}

Neste rol de perguntas, o primeiro questionamento se refere à participação dos estudantes em projetos educacionais relevantes para as questões pertinentes à gestão ambiental. Percebe-se, frente ao questionado, que a maioria ( $84 \%$ ) dos professores afirmou que seus alunos se envolvem em projetos escolares voltados para temáticas ambientais (GRÁFICO 03). Este resultado se distancia um pouco do remetido por Alcócer et.al. (2015), onde aponta que apenas 53,03\% dos alunos afirmam se envolver em projetos educacionais relacionados ao desenvolvimento sustentável. Os dados também diferem dos obtidos por Menezes e Rodrigues (2015), onde apenas 46\% dos alunos afirmam se envolver.

Diante dos resultados obtidos neste estudo, e dos resultados relatados por Alcócer et. al. (2015) e Menezes e Rodrigues (2015), pode-se supor que as divergências encontradas podem estar relacionadas ao público entrevistado, onde nos estudos relatados a pesquisa foi realizada apenas com alunos, mostrando a concepção dos mesmos, e no presente estudo mostra-se a visão dos educadores, frente à realidade pesquisada.

No âmbito, ainda, das atividades desenvolvidas pela escola que promovem diretamente ou parcialmente a gestão ambiental, é questionado acerca da realização de eventos escolares com temas associados à sustentabilidade, educação ambiental e gestão do meio ambiente. $\mathrm{O}$ resultado obtido indica que a maioria (58\%) dos entrevistados considera que os eventos escolares associados às questões ambientais ocorrem quase sempre, revelando, assim, uma sistematização na ocorrência de tais eventos (GRÁFICO 04).

A aprendizagem social é um processo que tenta responder às dificuldades encontradas no desenvolvimento sustentável e na integração das interfaces de uma gestão ambiental colaborativa. 
Pois isso pressupõe a integração entre as diferentes áreas de conhecimentos, numa abordagem metodológica transdisciplinar que envolve os segmentos de compreensão das interfaces e complexidade do campo educativo-ambiental (JACOBI, 2009).

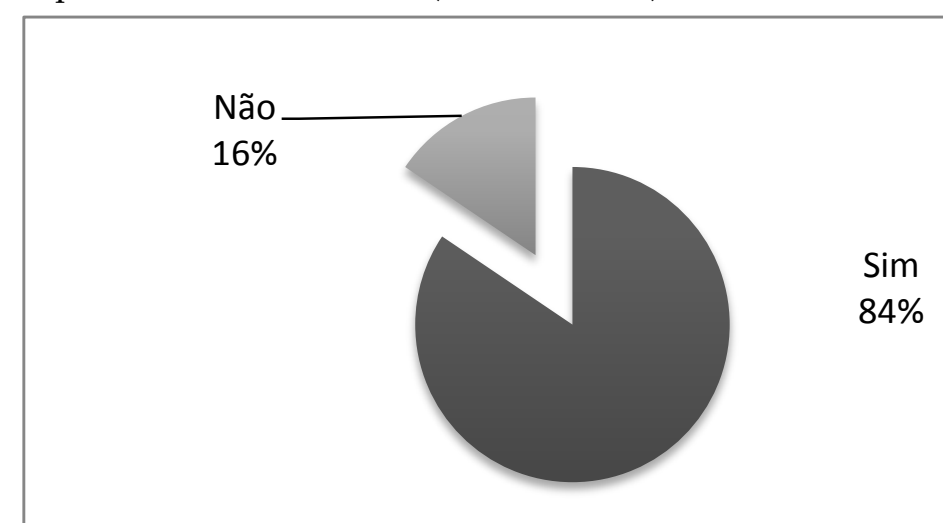

Gráfico 03 - Participação dos alunos em projetos escolares com temáticas ambientais Fonte: Elaborado pelos autores.

Neste aspecto do desenvolvimento social dos indivíduos para as questões ambientais, dentro do meio escolar, a oferta de eventos escolares pertinentes sobre questões como o gerenciamento dos resíduos sólidos, gestão dos recursos hídricos, poluição ambiental, desmatamento e aquecimentos global são temáticas que, quando exploradas, podem proporcionar aos educandos uma visão holística com relação à gestão ambiental (SABBAGH, 2011). Essa visão nos remete à ideia sobre o desenvolvimento sustentável, temática que normalmente é trabalhada nas escolas.

Ao serem indagados sobre a importância do tema sustentabilidade ser trabalhado em sala de aula, nas diferentes disciplinas, apenas um professor P30 afirmou que o referido tema não deve ser retratado em todas as disciplinas. Analisando-se o perfil deste professor, foi possível identificar que o mesmo leciona a disciplina de Química.

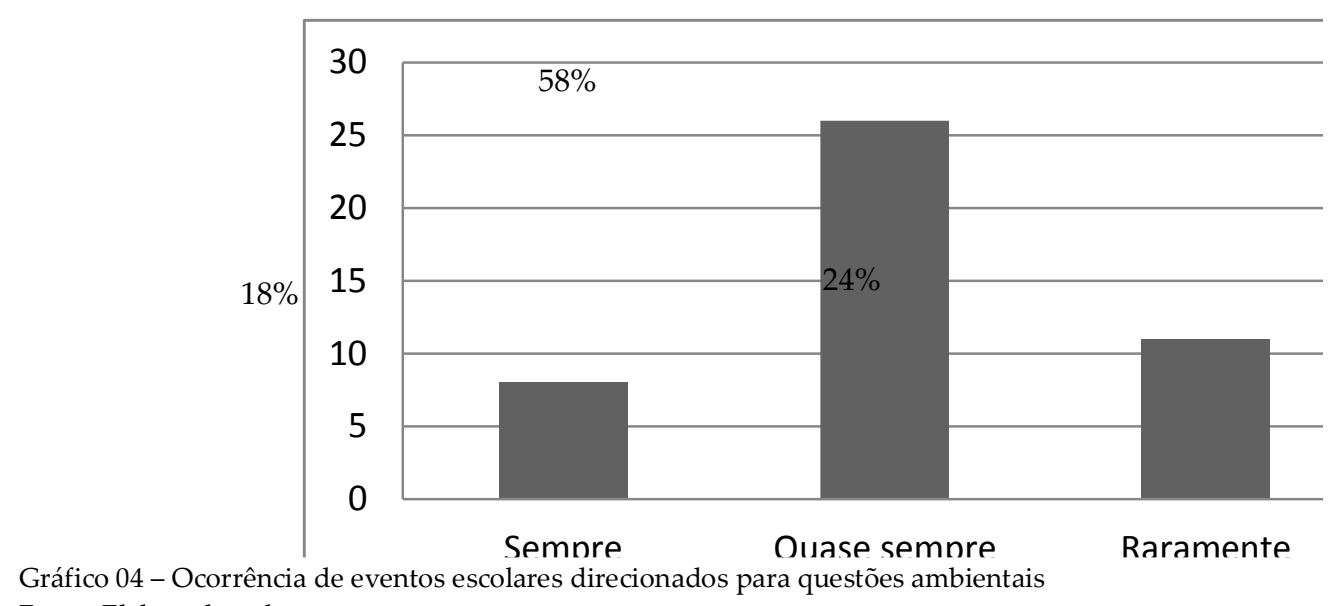

Fonte: Elaborado pelos autores.

Frente às concepções concebidas, a partir dos PCN, da importância da interdisciplinaridade e tendo-se o meio ambiente como um dos temas que são tratados como transversais (BRASIL, 2006), devendo ser trabalhado por todos os professores, percebe-se que existe uma divergência entre a opinião de P30 e aquilo que é remetido pelos PCN, onde configura que as temáticas ambientais devem ser trabalhadas em todas as escolas.

A educação básica por vezes comete falhas, não apenas por ser disciplinar, mas por não intensificar e orientar de forma complexa as capacidades cognitivas, inquisitivas e criativas dos estudantes e por estar desvinculada da problematização sociocultural e ambiental (DEMAJOROVIC; SILVA, 2012). Diante disso, torna-se extremamente necessário que se aborde essas questões de forma 
interdisciplinares nos parâmetros da dimensão pedagógica para que os educadores possam incorporar metodologias de ensino que contemplem as necessidades dos alunos.

Diante desta dimensão de interdisciplinaridade das temáticas vinculadas ao meio ambiente, questionou-se aos entrevistados se na escola em que eles atuam é frequente trabalhar com o tema sustentabilidade, motivando os alunos a adquirirem posturas sustentáveis, garantindo melhores condições de sobrevivência para as futuras gerações. Frente a este questionamento, identificou-se que $87 \%$ dos professores afirmaram que na sua escola esta abordagem é efetuada frequentemente (GRÁFICO 05). Alguns professores, além de afirmarem se é ou não frequente este tipo de abordagem, trouxeram a exemplificação das atividades que são promotoras para o desenvolvimento, como P8 “Acontece na Semana do Meio Ambiente; No Dia Mundial da Água; E creio que os professores (não todos, ainda) abordam em suas aulas".

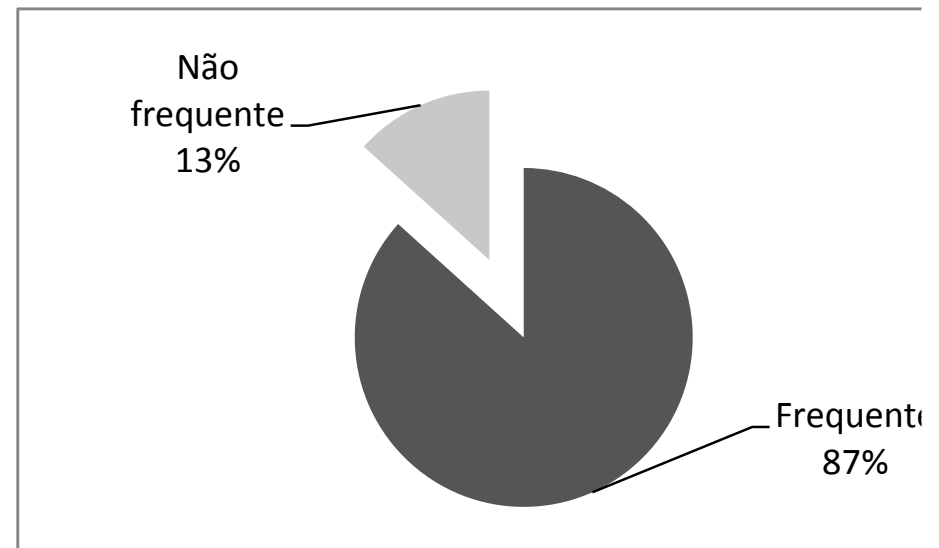

Gráfico 05 - Abordagem da temática sustentabilidade em escolas de Ensino Médio da rede estadual pesquisadas Fonte: Elaborado pelos autores.

Em meio ao posicionamento de P8, tem-se uma relação intrínseca entre os eventos escolares e a temática meio ambiente, correlacionada também por Menezes e Rodrigues (2015).

Esses resultados diferem dos obtidos por Silva e Tomé (2014), que de acordo com a sua pesquisa os estudantes afirmaram que a sustentabilidade é pouco trabalhada no cotidiano da escola, e deste modo seus conhecimentos tornam-se limitados às aquisições que ocorrem fora do contexto educacional, detendo-se ao senso comum, não possuindo um viés científico.

Além dos apontamentos feitos acerca das atividades desenvolvidas pelas escolas sobre a gestão ambiental, alguns professores como P14, ao afirmar que embora o tema seja desenvolvido com frequência, ainda é "muito limitado à questão ambiental e geográfica, sendo voltado especificamente no indivíduo. Faltando um debate maior nos aspectos sociais, políticos, econômicos". A procura pela sustentabilidade, portanto, leva a diversos conflitos na sociedade, pois enquanto os estudiosos da área desenvolvem discursos sobre a "população máxima", acabam por pecar no que se refere a expor a especificidade social e política que se correlaciona à apropriação dos recursos naturais. Os incentivos e prioridades associadas aos mecanismos e políticas de mercado maximizam a discrepância e reforçam os grandes atores da sociedade, poderosos que resistem à expansão dos controles democráticos (RATTNER, 1999).

Portanto, percebe-se nos discursos expostos que não é necessário apenas o desenvolvimento de estratégias de desenvolvimento do tema sustentabilidade, mas sim envolver os diversos setores sociais que se inserem de forma direta ou indireta no contexto da aquisição de políticas que permitam a preservação do meio ambiente por intermédio da sensibilização social.

\section{Considerações Finais}


Em meio aos resultados obtidos, observa-se que os professores apresentam uma concepção preliminar sobre a gestão ambiental, embora alguns desconheçam este conceito, e que as escolas promovem, mesmo que parcialmente, projetos e atividades que são promotoras da sensibilização para a sustentabilidade e o desenvolvimento sustentável.

Algumas práticas escolares como a coleta do papel, que é vendido para empresas que trabalham com a reciclagem, é vista como um método bastante eficiente para desenvolver a educação ambiental, de forma integradora, nos diversos seguimentos da escola. A participação dos alunos em projetos escolares promovendo eventos sobre as questões ambientais é vista como satisfatória, uma vez que possibilita aos estudantes uma visão global da realidade ambiental.

Pode-se perceber também que a gestão de resíduos sólidos ainda não ocorre de forma correta no município, já que não há aterros sanitários, sendo os resíduos sólidos despejados nos lixões, ocasionando uma série de desvantagens para a saúde da população. Outro fator também é a falta de incentivo para a coleta seletiva por meio dos gestores municipais, influenciando diretamente o cotidiano das escolas.

\section{Agradecimentos}

Aos revisores e colaboradores deste estudo, assim como a Fundação Cearense de Apoio ao Desenvolvimento Científico e Tecnológico - FUNCAP.

\section{Referências}

Alcócer JC A, Rodrigues AM, Pinto ALA, Silva CHF, Barroso HO, Oliveira MM, Martins VEP, Fonseca AM, Souza DF. Tecnologias Sustentáveis, Sustentabilidade e Práticas Pedagógicas nas Escolas de Ensino Médio. Revista Científica Linkania Master. 2015; v. 5, n. 1: p. 149-169.

Couto S. Gestão ambiental: o caminho da sustentabilidade. Acesso em: jul. de 2015. Disponível em: http://www.academiadetalentos.com.br/05.pdf.

Cuperschmid NRM, Tavares MC. Atitudes em relação ao meio ambiente e sua influência no processo de compra de alimentos. RIMAR. 2015; v. 1, n. 3: p. 5-14.

Demajorovic J, Silva HCO. Formação interdisciplinar e sustentabilidade em cursos de administração: desafios e perspectivas. RAM. 2012; v. 13, n. 5: p. 39-54.

Fernandes C. O capitalismo e o Advento de uma sociedade de consumo. Colégio Mãe de Deus. 2010; v. 1 n. 1 :

Freitas VP. Direito administrativo e meio ambiente. Revista da Faculdade de Direito UFPR. 2010; v. 27: p. 223-60

Gouvêa GRR. Rumos da formação de professores para a Educação Ambiental. Educar em revista. 2006; n. 27: p. 163-179.

Jacobi, PR, Tristão M, Franco MIGC. A função social da educação ambiental nas práticas colaborativas: participação e engajamento. Cad Cedes. 2009; v. 29, n. 77: p. 63-79.

Kraemer MEP. Gestão ambiental: um enfoque no desenvolvimento sustentável. Itajaí/SC: Univali, 2004. Acesso em: mai. de 2014. Disponível em: http://www.gestiopolis.com/gestao-ambiental-umenfoque-no-desenvolvimento-sustentavel/.

Lei no . 6.938/81, de 31 de agosto de 1981. Dispõe sobre a Política Nacional do Meio Ambiente. Diário

Oficial da União (Brasília). 1981 Set 02. 
Matos KSL, Vieira SL. Pesquisa educacional: o prazer de conhecer. Fortaleza: Edições Demócrito Rocha. 2002.

Menezes JBF, Rodrigues AM. Sustentabilidade como tema de práticas pedagógicas na Escola Estadual de Educação Profissional Alfredo Nunes de Melo em Acopiara (CE). RevBEA. 2015; v. 10, n. 2: p. 73-84.

Piovesan A, Temporini ER. Pesquisa exploratória: procedimento metodológico para o estudo de fatores humanos no campo da saúde pública. Rev Saúde Pública. 1995; v. 29, n. 4: p. 318-25.

Prodanov CC, Freitas EC. Metodologia do Trabalho Científico: Métodos e Técnicas da Pesquisa e do Trabalho Acadêmico-2 ${ }^{a}$ Edição. Editora Feevale. 2013.

Rattner, H. Sustentabilidade-uma visão humanista. Ambiente \& sociedade. 1999; n. 5: p. 233-240.

Rodrigues LF, Cavinatto VM. Lixo: de onde vem? Para onde vai? São Paulo: Moderna, 1997.

Rodrigues, MSB. Crenças e comportamentos de usuários do restaurante universitário da Universidade de Brasília [disertation]. Mestrado em Educação-Universidade de Brasília, Brasília, 2012: 115 f.

Sabbagh RB. Gestão Ambiental. Cadernos de Educação Ambiental. 2011; Estado de São Paulo Secretaria do Meio Ambiente.

Secretaria de Educação Básica, Ministério da Educação. Orientações Curriculares para o Ensino Médio. Brasília (Brasil): Ministério da Educação, 2006. p. 37.

Silva TBM; Tomé CL. O discurso pedagógico e o conceito de sustentabilidade no discurso do professor e do aluno da Educação de Jovens e Adultos. REP’s. 2014; v. 5, n. 2: p. 321-329. 